\title{
Unusual Cases of the Transmigrated Mandibular Canines: Report of 4 Cases
}

\author{
Ali Murat Aktan \\ Sami Kara ${ }^{a}$ \\ Faruk Akgunlu \\ Eren Isman' \\ Siddik Malkoc ${ }^{d}$
}

\begin{abstract}
The canine impaction is not uncommon in dental literature, but the transmigration of mandibular canine is a rare phenomenon, and some of them are far more extreme than others. In this study, we aimed to present the more extreme cases of the four transmigrated mandibular canine cases with special emphasis on their classification. (Eur J Dent 2008;2:122-126)
\end{abstract}

Key words: Impaction; Transmigration; Canine; Panoramic radiograph.

\section{INTRODUCTION}

In dental literature, cases of transmigrated mandibular canines are uncommon phenomenon. ${ }^{1-19}$ However some of them are far more extraordinary than others. Although transmigration of a tooth is out of the common, migration generally to apexes of molars is more uncommon event when compared with teeth which generally migrates to apixes of the incisor teeth. Besides, bilateral ones in vertical position may be more extreme than the others even though

- a Research Assistant, Department of Oral Diagnosis and Radiology, Faculty of Dentistry, Selcuk University, Konya, Turkey.

b Professor and Department Chair, Department of Oral Diagnosis and Radiology, Faculty of Dentistry, Selcuk University, Konya, Turkey.

c Research Assistant, Department of Orthodontics, Faculty of Dentistry, Selcuk University, Konya, Turkey.

d Associate Professor, Department of Orthodontics, Faculty of Dentistry, Selcuk University, Konya, Turkey.

- Corresponding author: Ali Murat Aktan Selçuk Üniversitesi, Dișhekimliḡi Fakültesi, Oral Diagnoz ve Radyoloji A.D.

Kampus, Konya, 42079, Turkey

E-mail: dtmurataktandyahoo.com.tr bilateral cases in horizontal position are extreme. Likewise, cases which reported in the past were consisted of only maxillary or mandibular canine teeth until Camilleri $^{3}$ discovered that multiple transmigration was also be more extreme than the others. However, we have aimed to present the more extreme cases of the transmigrated mandibular canines.

\section{CASE REPORTS}

\section{Case 1}

TK, 21 year-old girl, referred to our clinic complaining of a pain arising from her right mandibular permanent first molar. On intraoral examination, left mandibular deciduous canine was seen to be retained. Panoramic radiograph revealed that horizontally impacted left mandibular permanent canine migrated crossing the midline located below the apices of the right mandibular second molar. The transmigrated canine located near the mandibular canal but there was no symptom associated with mandibular canal including; paresthesia, paralysis or pain. The migrated canine also showed no evidence of 
resorption or pericoronal radiographic changes suggesting cystic degeneration. The radiographic appearance was in accordance with Type $4^{17}$ (Figure 1).

\section{Case 2}

A 16 year old girl had pain in the lower right third molar. Oral examination revealed that right mandibular canine was missing in the original arch and there was a swelling in the labial aspect of the symphsis. Panoramic radiograph revealed that right mandibular canine was impacted and crossing the midline under the apixes of the incisors and there was a compound odontoma in the original position of the right canine. The radiographic appearance was in accordance with Type ${ }^{17}$ (Figure 2).

\section{Case 3}

A 28 year old woman turned to our clinic about the examination of her peridontal status. During the oral examination bilaterally overretained deciduous canines were observed and permanent canines were missing in the lower jaw clinically. The patient was unaware of her condition. Panoramic radiograph revealed bilaterally impacted canines lying vertically in the midline in the apices of the incisors. There was no any resorption on the deciduous canine. The radiographic appearance was in accordance with Type $5^{17}$ (Figures 3 and 4).

\section{Case 4}

A 76 year old woman resorted to our clinic about the pain in right mandibular permanent first molar. The panoramic radiograph indicated that multiple teeth were impacted horizontally with part of the crowns crossing the midline. Occlusal radiograph delineated that three teeth were impacted including right mandibular permanent canine and two mandibular permanent incisors, and it confirmed transmigration of these teeth. Patient was not aware of her condition (Figures 5 and 6).

\section{DISCUSSION}

This paper consists of some unusual cases of transmigration of the mandibular permanent canines such as, bilateral cases of the transmigrated canines in vertical position, one of the the most distant migration of canine from original side to contralateral to the apex of the third molar, and multiple transmigration case with transmigrated mandibular canine and impacted mandibular central incisors.

The movement of a tooth is always in the direction of the crown, and most often the greatest amount of movement takes place prior to completion of tooth root development or at an earlier stage. ${ }^{8}$ Ando et al ${ }^{15}$ reported that movement of transmigrated canine was more rapid before the formation of its root. Because of patient's age, it can be suggested that the greatest amount of movement occurred before completion of the root formation in case 1.

Rarely transmigrated canine was found under the first molar on the opposite side of the dental arch. ${ }^{1,6}$ Auluck reported that presence of a canine migrated apical to the mesial aspect of right third molar. ${ }^{9}$ It was found that the transmigrated canine was lying horizontally under the second molar on the opposite side as shown in case 1. The transmigrated canine in this case was one of the most migrated teeth concerning literature just as Auluck's case.

Joshi reported that $70.8 \%$ of the cases were overretained deciduous canines and $29.2 \%$ of the cases were exfoliated in the mandibular arch. ${ }^{1}$ This observation showed that resorption process of the root of the deciduous canine was rather slow in the absence of the developing permanent mandibular canine under the deciduous canine. In case 1, over retained left deciduous canine was intact supporting Joshi's findings.

There are several reports related to transmigrated teeth pathologies including; a cyst or an odontoma, ${ }^{10,11}$ Gardner's syndrome, ${ }^{12}$ or fracture. ${ }^{13}$ Although Nodine ${ }^{14}$ and Ando et al ${ }^{15}$ reported that impacted and migrated mandibular canines were often discovered without producing any apparent symptoms and they did not observe any symptoms such as pain or oppression of mandibular nerve owing to the transmigration of canine in their patients, Joshi ${ }^{1}$ reported that it was difficult to understand whether these pathologies were responsible for the transmigration process or the pathological situations occurred after the migration of the canine. In case 2, there was a compound odontoma which was associated with impaction or transmigration. In case 4. etiology was likely to be trauma, but we could not suggest 
any apparent reason of how or why canines had transmigrated in case 1 and in case 3 . Although Peck $^{20}$ reported that canine migration was congenitally inherited, none of closed relatives of the patients had this abnormality. A consensus on exact mechanism of transmigration has not been reached in literature yet. As a consequence, further studies may include genetic researches as an incomprehensible matter in this phenomenon.

Multiple transmigrations are even rare. Camileri ${ }^{3}$ firstly reported multiple transmigration case including mandibular canine and lateral incisors. A patient with transmigrated mandibular

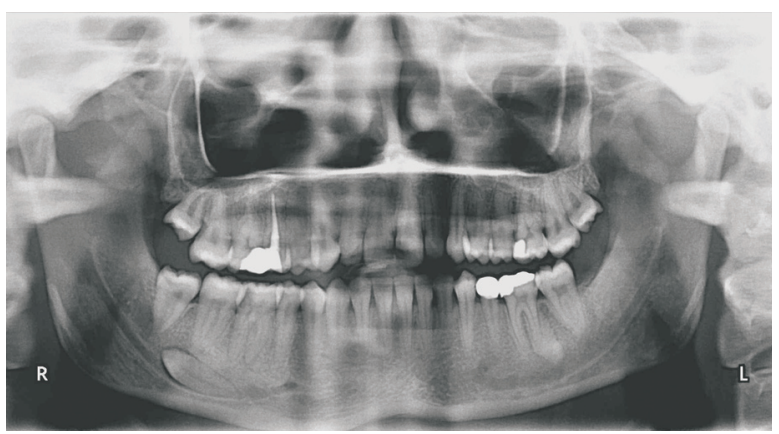

Figure 1. Panoramic radiograph showing transmigrated left canine extending from left side to opposite side and located below the apices of the right mandibular second molar.

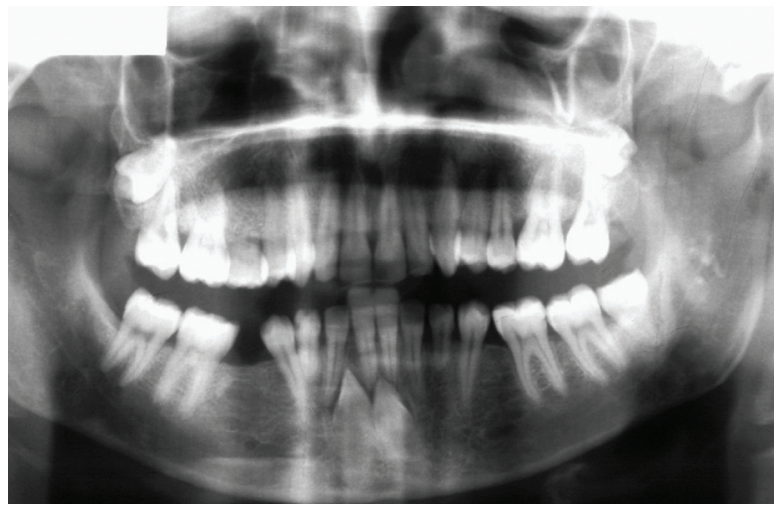

Figure 3. Bilaterally impacted canines located below the apices of the incisors in vertical position.

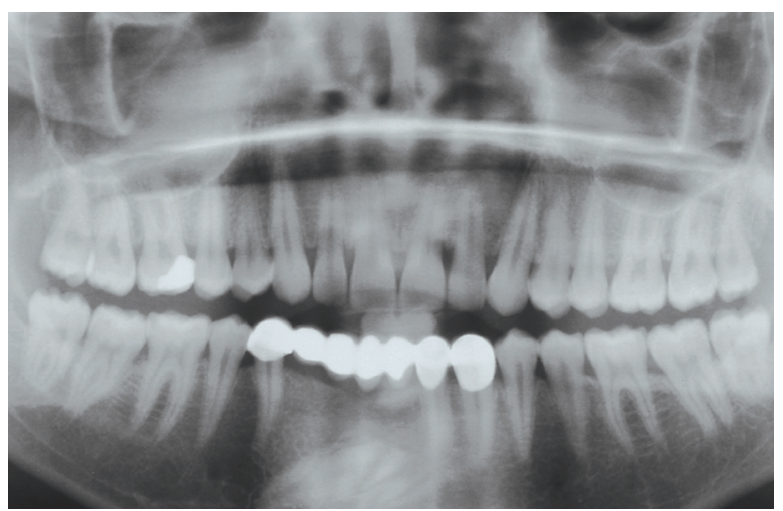

Figure 5. Transmigrated mandibular right canine is impacted with some incisor teeth. right canine and impacted two lower incisors probably related to earlier trauma was presented in case 4. But, unfortunately, it is not sure whether these teeth were central or lateral incisor without surgery. According to Camileri, ${ }^{3}$ impacted mandibular lower incisor teeth might be called as transmigrated teeth. This case showed that eruption abnormalities might affect more than one type of tooth. ${ }^{16}$

While most of the transmigrated mandibular canines occurred unilaterally, $1,2,4,5,7,9,11,17,19$ only $9 \%$ of them were bilateral.1,6 Although most of the bilateral transmigrated canines lied horizontally,

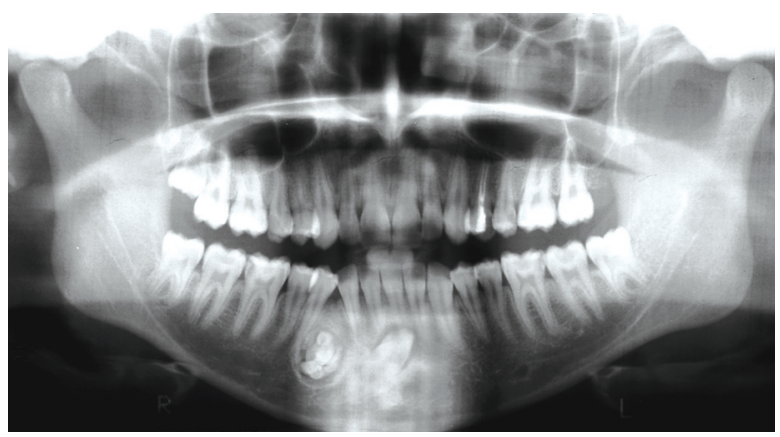

Figure 2. Radiograph showing impacted right mandibular canine tooth is associated with compound odontoma.

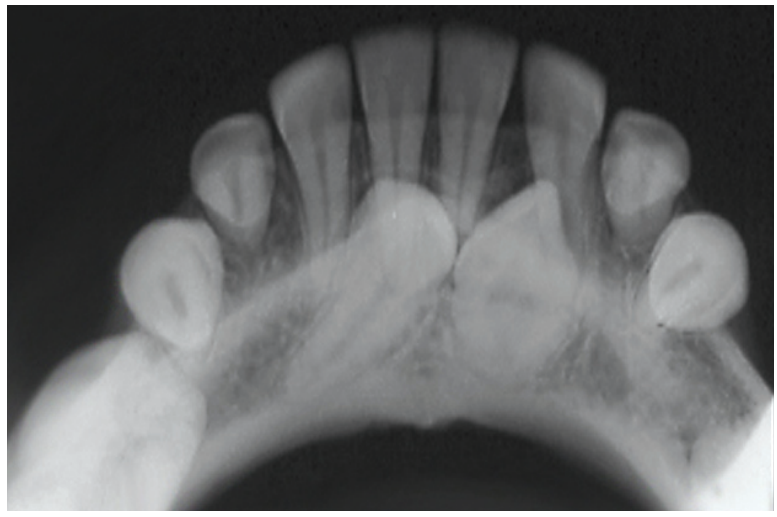

Figure 4. Occlusal radiograph showing bilaterally impacted canines in vertical position.

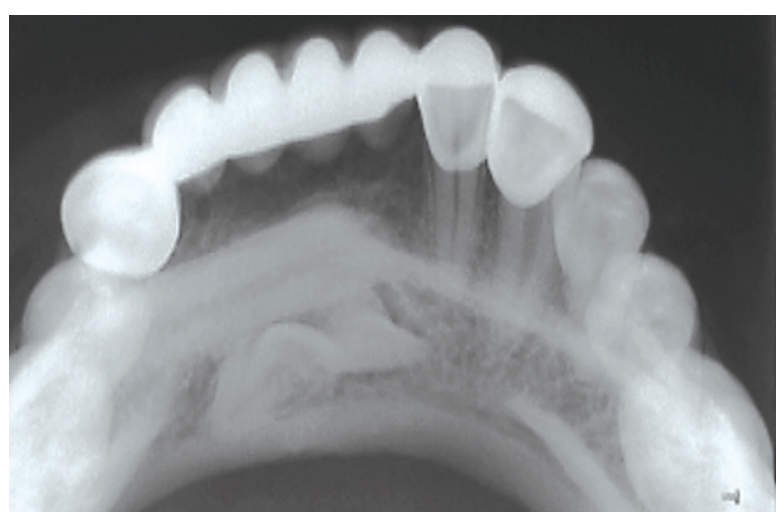

Figure 6. Occlusal radiograph showing impacted incisors. 
there were no bilateral transmigrated teeth which were in vertical position. In case 3 , while 33 lied vertically in the midline, 43 lied vertically between apices of the 41 and 42 because of inadequate space to cross. It can not be suggested that both canines crossed the midline completely. In bilateral transmigration cases which canines lied in vertical position, it is impossible for both canines to cross the midline simultaneously.

Transmigrated mandibular canines were classified according to Mupparapu. ${ }^{17}$ It could be summarized as;

Type 1: The impacted canine is mesioangularly acrossing the midline, labial, or lingual to the anterior teeth with the crown portion of the tooth crossing the midline.

Type 2: The canine is horizontally impacted near the inferior border of the mandible below the apices of the incisors.

Type 3: The canine has erupted either mesial or distal to the opposite canine.

Type 4: The canine is horizontally impacted near the inferior border of the mandible below the apices of either premolars or molars on the opposite side.

Type 5: The canine is positioned vertically in the midline with the long axis of the tooth crossing the midline.

Mupparapu's classification consisted of single transmigrated canine. In case 3 , bilateral impacted canines in vertical position located in the midline was in accordance with Type 5.

Besides the option of surgical removal, transplantation and surgical exposure with orthodontic alignment are treatment alternatives for the transmigrated teeth. ${ }^{2}$ A long term follow up without symptoms may be an alternative option for patients who are afraid of surgical processes. Migrated tooth must be detected in early stages of its migration for orthodontic treatment. If it can not be detected early, further treatment alternatives will lessen and the case might get worse. Surgical extraction is more appropriate than others in case of a pathological situation. Consequently, decision of treatment options relates to pathological conditions, location and position of the transmigrated tooth and patient's desire. In present study, only one of our 4 patients preferred surgical treatment (in case 2) and others went under follow up.
The transmigrated canine, which was the subject of case 1, located near the mandibular canal. The report of Brust ${ }^{18}$ clearly showed that the transmigrated canine maintained its nerve supply from the original site. Although the most probable treatment option is to keep the transmigrated teeth under critical observation with periodical panoramic examination, it is necessary to anesthetize the nerve bilaterally before the surgical extraction with local anesthesia in case of unexpected pathological condition.

\section{CONCLUSIONS}

To conclude so far, some cases of them are rather extreme cases even though transmigration of mandibular canine is an unusual event. These cases have been increasing day by day. It is important to diagnose them in earlier stages of migration or abnormality to prevent more complicated situations. From the aspect of genetic factors, a lot of questions about etiology still remains unanswered, Therefore detailed mechanisms of the transmigration origin is a subject of further genetic researches.

\section{REFERENCES}

1. Joshi MR. Transmigrant mandibular canines: A record of 28 cases and a retrospective review of the literature. Angle Orthod 2001;71:12-22.

2. Camileri S, Scerri E. Transmigration of mandibular canines: A review of the literature and a report of five cases. Angle Orthod 2003;73:753-762.

3. Camileri S. Double transmigration and hyperdontia. Angle Orthod 2007;77,4:742-744.

4. Aydin U, Yilmaz HH. Transmigration of impacted canines. Dentomaxillofac Radiol 2003;32:198-200.

5. Greenberg S, Orlian A. Ectopic movement of an unerupted mandibular canine. J Am Dent Assoc 1976;93:125-128.

6. Joshi MR, Daruwala NR, Ahuja HC. Bilateral impaction of mandibular canines. Br J Orthod 1982;9:57-58.

7. O'Carroll MK. Transmigration of the mandibular right canine with development of odontoma in its place. Oral Surg Oral Med Oral Pathol 1984;57:349.

8. Stafne EC. Malposed mandibular canine. Oral Surg Oral Med Oral Pathol 1963;16:1330.

9. Auluck A, Nagpal A, Setty S, Pai KM, Sunny J. Transmigration of impacted mandibular canines-report of 4 cases. $J$ Can Dent Assoc 2006;72:249-252.

10. Shapira $Y$, Kuftinec MM: Intrabony migration of impacted teeth. Angle Orthod 2003;73:738. 
11. Al-Whaeidi EMH. Transmigration of unerupted mandibular canines: A literature review and a report of five cases. Quintessence Int 1996;27:27-31.

12. Baykul T, Heybeli N, Oyar O, Doḡru H. Multiple huge osteomas of the mandible causing disfigurement related with Gardner's syndrome: case report. Auris Nasus Larynx 2003;30:447-451.

13. Mitchell L. Displacement of a mandibular canine following fracture of the mandible. Br Dent $J$ 1987;163:236.

14. Nodine AM. Abberant teeth, their history, causes and treatment. Dent Items of Interest 1943;65:440-451.Cited by: Joshi MR. Transmigrant mandibular canines: a record of 28 cases and a retrospective review of the literature. Angle Orthod 2001;71:12-22.

15. Ando S, Aizaea K, Nakashima T, SankaY, Shimbo K, Kiyokawa $\mathrm{K}$. Transmigration process of impacted mandibular cuspid. J Nihon Univ Sch Dent 1964;6:66-71.

16. Bjerklin K, Kurol J, Valentin J. Ectopic eruption of maxillary first permanent molars and association with other tooth and developmental disturbances. Eur J Orthod 1992;14:369375.

17. Mupparapu M. Patterns of intra-osseos transmigration and ectopic eruption of mandibular canines: review of literature and report of nine additional cases. Dentomaxillofac Radiol 2002;31:355-360.

18. Bruszt P. Neurological anomaly associated with extreme malposition of a mandibular canine. Oral Surg Oral Med Oral Pathol 1958;11:89-90. Cited by: Joshi MR. Transmigrant mandibular canines: a record of 28 cases and a retrospective review of the literature. Angle Orthod 2001;71:12-22.

19. Aydin U, Yilmaz HH, Yildirim D. Incidence of canine impaction and transmigration in a patient population. Dentomaxillofac Radiol 2004;33:164-169.

20. Peck S. On the phenomenon of intraosseous migration of nonerupting teeth. Am J Orthod Dentofacial Orthop 1998;113:515-517. 